University of Nebraska - Lincoln

DigitalCommons@University of Nebraska - Lincoln

\title{
Endovascular balloon occlusion of the aorta is superior to resuscitative thoracotomy with aortic clamping in a porcine model of hemorrhagic shock
}

\author{
Joseph M. White \\ Lackland Air Force Base \\ Jeremy W. Cannon \\ The Uniformed Services University of the Health Sciences \\ Adam Stannard \\ Royal Centre for Defence Medicine \\ Nickolay P. Markov \\ Lackland Air Force Base \\ Jerry R. Spencer \\ Lackland Air Force Base \\ See next page for additional authors \\ Follow this and additional works at: https://digitalcommons.unl.edu/usuhs \\ Part of the Medicine and Health Sciences Commons
}

White, Joseph M.; Cannon, Jeremy W.; Stannard, Adam; Markov, Nickolay P.; Spencer, Jerry R.; and Rasmussen, Todd E., "Endovascular balloon occlusion of the aorta is superior to resuscitative thoracotomy with aortic clamping in a porcine model of hemorrhagic shock" (2011). Uniformed Services University of the Health Sciences. 88.

https://digitalcommons.unl.edu/usuhs/88

This Article is brought to you for free and open access by the U.S. Department of Defense at DigitalCommons@University of Nebraska - Lincoln. It has been accepted for inclusion in Uniformed Services University of the Health Sciences by an authorized administrator of DigitalCommons@University of Nebraska Lincoln. 


\section{Authors}

Joseph M. White, Jeremy W. Cannon, Adam Stannard, Nickolay P. Markov, Jerry R. Spencer, and Todd E. Rasmussen 


\title{
Endovascular balloon occlusion of the aorta is superior to resuscitative thoracotomy with aortic clamping in a porcine model of hemorrhagic shock
}

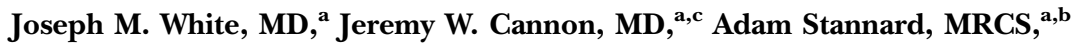 \\ Nickolay P. Markov, MD, ${ }^{\mathbf{a}}$ Jerry R. Spencer, RVT, ${ }^{\mathbf{a}}$ and Todd E. Rasmussen, MD, ${ }^{\mathbf{a}, \mathbf{c}}$ San Antonio, TX, \\ Birmingham, UK, and Bethesda, MD
}

\begin{abstract}
Background. Noncompressible torso hemorrhage is the leading cause of potentially preventable death on the modern battlefield. The objective of this study is to characterize resuscitative aortic balloon occlusion (BO) compared to thoracotomy with aortic clamping in a model of hemorrhagic shock.

Methods. A total of 18 swine (3 groups; 6 animals/group) were used in this study. Swine in class IV shock underwent no aortic occlusion (NO), thoracotomy and clamp occlusion (CO), or endovascular BO. Animals in the NO group underwent direct placement of a temporary vascular shunt (TVS) at the injury site, whereas animals in the $C O$ and $B O$ groups underwent aortic occlusion before TVS placement. Hemodynamic and physiologic measures were collected.

Results. The central aortic pressure, carotid blood flow and brain oxygenation as measured by oximetry increased in the $C O$ and $B O$ groups compared to the $N O$ group $(\mathrm{P}<.05)$. During resuscitation, the BO group was less acidotic than the $C O$ group $(p H, 7.35$ ws $7.24 ; \mathrm{P}<.05)$ with a lower serum lactate level (4.27 vs 6.55; $\mathrm{P}<.05)$ and pCO2 level (43.5 vs 49.9; $\mathrm{P}<.05)$. During resuscitation, the BO group required less fluid $(667 \mathrm{~mL}$ vs $2,166 \mathrm{~mL} ; \mathrm{P}<.05)$ and norepinephrine $(0 \mathrm{mcg}$ vs $52.1 \mathrm{mcg} ; \mathrm{P}<.05)$ than the CO group.

Conclusion. Resuscitative aortic BO increases central perfusion pressures with less physiologic disturbance than thoracotomy with aortic clamping in a model of hemorrhagic shock. Endovascular BO of the aorta should be explored further as an option in the management of noncompressible torso hemorrhage. (Surgery 2011;150:400-9.)
\end{abstract}

From Wilford Hall United States Air Force Medical Center, ${ }^{a}$ Lackland Air Force Base, San Antonio, TX; The Academic Department of Military Surgery and Trauma, ${ }^{b}$ Royal Centre for Defence Medicine, Birmingham, UK; and the Norman M. Rich Department of Surgery, ${ }^{c}$ The Uniformed Services University of the Health

Sciences, Bethesda, $M D$

NONCOMPRESSIBLE TORSO HEMORRHAGE is the leading cause of potentially preventable death on the battlefield..$^{1-3}$ If not treated promptly, hemorrhage leads to

The results of this study and opinions expressed in the manuscript are the views of the authors and are not to be construed as official statements by or as a reflection of the views of the U.S. Department of the Air Force, the U.S. Department of the Army, or the U.S. Department of Defense.

Presented at the 6th Annual Academic Surgical Congress Huntington Beach, CA, February 1-3, 2011.

Accepted for publication June 13, 2011.

Reprint requests: Todd E. Rasmussen, MD, Deputy Commander, US Army Institute of Surgical Research, 3400 Rawley E. Chambers/Suite B, Fort Sam Houston, TX 78236. E-mail: todd. rasmussen@amedd.army.mil.

0039-6060/\$ - see front matter

Published by Mosby, Inc.

doi:10.1016/j.surg.2011.06.010 cardiovascular collapse and death. While tourniquets have proven utility in controlling extremity hemorrhage, useful measures to manage shock in the setting of torso injury remain elusive., ${ }^{4,5}$

In 1976, Ledgerwood reported experience with resuscitative thoracotomy with aortic clamping; a maneuver to sustain central pressure and control hemorrhage in the setting of hemoperitoneum and shock. ${ }^{6}$ This technique is maximally invasive and survival following its performance is rare. However, with no alternative, resuscitative thoracotomy has been incorporated into civilian and military clinical guidelines. ${ }^{7-10}$

The emergence of endovascular aortic aneurysm repair has resulted in the development of balloons to occlude the aorta and expand endograft components. ${ }^{11}$ Aortic balloons have also been shown to be effective in the setting of ruptured 
aneurysms; a scenario which is comparable to noncompressible torso hemorrhage. In this context balloons are positioned and inflated in the aorta proximal to the rupture to support central pressure and reduce bleeding while resuscitation and anesthesia are initiated. ${ }^{12-14}$ Endovascular aortic balloon occlusion is now preferred as the initial maneuver in this setting and has been credited with a significant improvement in survival. ${ }^{12-14}$

Despite success in the management of aneurysms, the effectiveness of resuscitative aortic balloon occlusion in the setting of noncompressible hemorrhage from trauma is not known. Additionally this endovascular technique has not been compared to thoracotomy and clamping in a large animal model. The objective of this study is to characterize the physiologic impact of aortic balloon occlusion in a model of torso hemorrhage and shock. An additional objective is to compare the effectiveness of this technique to thoracotomy with aortic clamping.

\section{MATERIALS AND METHODS}

Study approval and overview. Institutional Animal Care and Use Committee (IACUC) approval was obtained from our institution before the study was undertaken. Procedures were performed at an accredited facility (Lackland Air Force Base, San Antonio, TX) in compliance with IACUC policies and under the supervision of a licensed veterinary staff. Female Yorkshire-Landrace crossbred swine (John Albert, Cibolo, TX) (age range, 5-6 months; weight range, $70-95 \mathrm{~kg}$ ) were housed at the facility 7 days before the protocol to allow for quarantine and acclimation. Animals were exposed to 4 study phases as follows: baseline (BL), injury, operative, resuscitation (Fig 1).

The BL phase included induction of anesthesia and placement of vascular access with initial collection of blood for laboratory analysis. The injury phase included simulated prehospital hemorrhage $\left(\mathrm{t}_{\text {minus20 }}\right.$ to $\mathrm{t}_{0}$ minutes $)$ and transport ( $t_{0}$ to $t_{10}$ minutes). For purposes of the study, transport was defined as a "best case scenario" time needed to convey a patient to a trauma center. Time zero $\left(t_{0}\right)$ was designated as the time after completion of prehospital hemorrhage and the start of a simulated transport. The operative phase comprised maneuvers to manage the vascular injury and initiate resuscitation $\left(t_{10}\right.$ to $t_{60}$ minutes). Finally, the resuscitation phase $\left(t_{60}\right.$ to $t_{360}$ minutes) included administration of crystalloid and norepinephrine and collection of blood for analyses.
Phases of protocol (Fig 1). During the injury phase, the animals were hemorrhaged through an iliac artery sheath. The operative phase differed in the sequence of maneuvers used in the approach to the iliac artery sheath. The animals were placed in 3 groups $(\mathrm{N}=6$ /group) to correspond with the 3 types of maneuvers used. The clamp occlusion (CO) group underwent left thoracotomy with aortic clamping followed by laparotomy and iliac artery control. The balloon occlusion (BO) group underwent $\mathrm{BO}$ of the thoracic aorta followed by laparotomy and vascular control. The no occlusion (NO) group underwent laparotomy with direct control of the iliac artery without aortic occlusion. Arterial control in the $\mathrm{CO}$ and $\mathrm{BO}$ groups was performed after aortic occlusion and consisted of exploration of the iliac artery.

After sheath removal, limb reperfusion was established with a temporary vascular shunt (TVS) (Sundt; Integra LifeSciences, Plainsboro, NJ). After TVS placement in the $\mathrm{CO}$ and $\mathrm{BO}$ groups, aortic occlusion was released. During resuscitation, animals underwent monitoring and laboratory analyses. Crystalloid and norepinephrine were administered to sustain a goal aortic pressure $\geq 60$ $\mathrm{mm} \mathrm{Hg}$.

Operative technique. Anesthesia was induced with ketamine and maintained with a range of $2 \%$ to $4 \%$ isoflurane. Animals underwent similar operative procedures that included exposure of the right carotid artery and jugular vein, as well as exposure of the right brachial artery for monitoring. A carotid flow probe (Transonic Systems, Inc., Ithaca, NY) was placed on the right common carotid artery and central venous access established with a catheter placed in the right jugular vein. Using fluoroscopic guidance, a right brachial arterial line was directed into the aortic arch to enable measurement of central aortic pressure.

Throughout the protocol, the following measurements were monitored: heart rate, temperature, end-tidal carbon dioxide, and pulse oximetry; partial pressure brain tissue oximetry (Licox; Integra NeuroSciences, Plainsboro, NJ) and transcutaneous infrared brain oximetry (Pediatric SomaSensor;Somanetics Corporation, Troy, MI).

During the operative phase, the aorta was clamped through a left thoracotomy in the CO group with elimination of flow confirmed by duplex ultrasonography (z.one ultra ${ }^{\mathrm{TM}}$ System, ZONARE Medical Systems, Inc., Mountainview, $\mathrm{CA})$. In the BO group, aortic occlusion was accomplished with an endovascular balloon (Coda Balloon; Cook Medical Inc, Bloomington, IN) in the thoracic aorta that was inflated distal to the left 


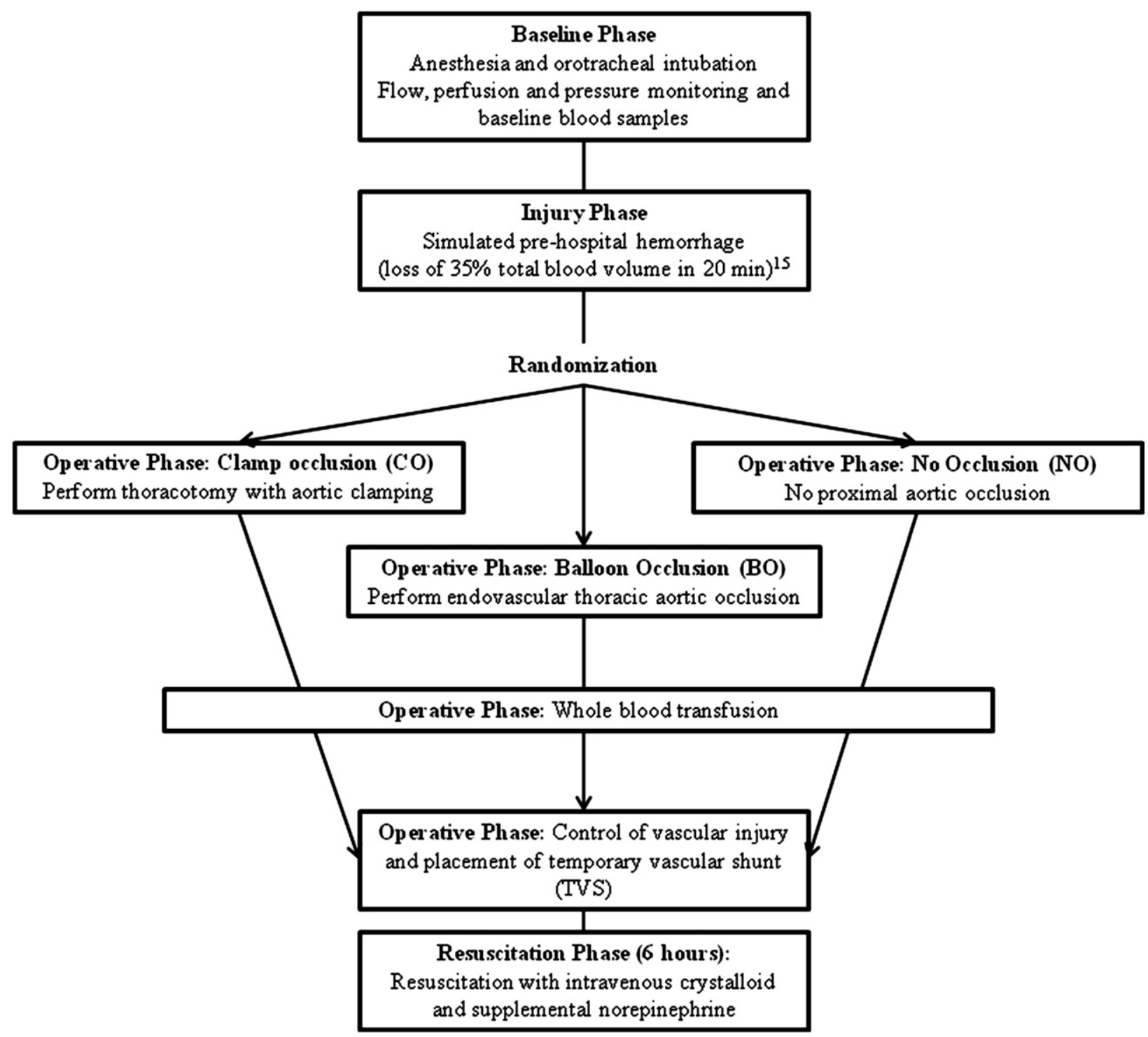

Fig 1. Diagram of 4 study phases: baseline, injury, operative and resuscitation. After the injury phase with hemorrhage to induce class IV shock, animals were randomized into 1 of 3 groups: thoracotomy with open aortic clamp occlusion (CO group), endovascular aortic balloon occlusion (BO group) or direct vascular control with no aortic occlusion (NO group). The operative phase also included initiation of whole blood resuscitation and placement of temporary vascular shunt (TVS) in the iliac artery injury site. After the operative phase, the animals experienced a 6-hour resuscitation phase during which measures of physiologic parameters and fluid and vasopressor requirements were measured.

subclavian artery. Using fluoroscopic guidance, the balloon was positioned into the thoracic aorta through a 14-French (Fr) sheath located in the right iliac artery. Once the balloon was inflated, complete aortic occlusion was confirmed by loss of the transduced arterial wave form from a catheter distal to the balloon placed through a left femoral artery sheath.

In the $\mathrm{CO}$ and $\mathrm{BO}$ groups, laparotomy with control of the iliac sheath site followed aortic occlusion and occurred prior to placement of the TVS (Table I: Operative phase pre-TVS). After placement of the TVS, extremity reperfusion was established in all groups. In the $\mathrm{CO}$ and $\mathrm{BO}$ groups, this reperfusion entailed release of the aortic clamp and deflation of the balloon, respectively (Table I).

Details of hemorrhage. A standardized method for blood volume estimation and rate of hemorrhage was used. ${ }^{15}$ In brief, to gauge hemorrhage rate and volume, the animal's weight was multiplied by an average estimate of total blood volume in adult swine $(66 \mathrm{~mL} / \mathrm{kg})$, which provided the total blood volume of the animal in milliliters $(\mathrm{mL})$. 
Table I. Comparison of perfusion measurements

\begin{tabular}{|c|c|c|c|}
\hline & Clamp occlusion & Balloon occlusion & No aortic occlusion \\
\hline \multicolumn{4}{|l|}{ Central aortic pressure $(\mathrm{mmHg})$} \\
\hline Baseline & $57 \pm 4$ & $59 \pm 4$ & $62 \pm 4$ \\
\hline End of injury phase $\left(\mathrm{t}_{10}\right)$ & $33 \pm 3$ & $37 \pm 3$ & $30 \pm 2$ \\
\hline Operative phase: pre-TVS & $138 \pm 12^{*}$ & $146 \pm 13^{*}$ & $45 \pm 4 \dagger, \ddagger$ \\
\hline Operative phase: post-TVS & $50 \pm 4$ & $66 \pm 5$ & $48 \pm 4$ \\
\hline Resuscitation phase $\left(\mathrm{t}_{60}\right)$ & $48 \pm 3$ & $62 \pm 3$ & $53 \pm 3$ \\
\hline Resuscitation phase $\left(t_{360}\right)$ & $57 \pm 2$ & $59 \pm 3$ & $59 \pm 3$ \\
\hline \multicolumn{4}{|l|}{ Carotid flow $(\mathrm{mL} / \mathrm{min})$} \\
\hline Baseline & $320 \pm 29$ & $259 \pm 24$ & $258 \pm 27$ \\
\hline End of injury phase $\left(\mathrm{t}_{10}\right)$ & $187 \pm 22$ & $174 \pm 20$ & $149 \pm 17$ \\
\hline Operative phase: pre-TVS & $1,085 \pm 110^{*}$ & $862 \pm 87 *$ & $262 \pm 27 \dagger$ \\
\hline Operative phase: post-TVS & $285 \pm 34$ & $353 \pm 42$ & $274 \pm 33$ \\
\hline Resuscitation baseline $\left(\mathrm{t}_{60}\right)$ & $321 \pm 30$ & $302 \pm 28$ & $300 \pm 27$ \\
\hline Resuscitation phase $\left(t_{360}\right)$ & $351 \pm 26$ & $313 \pm 24$ & $332 \pm 27$ \\
\hline \multicolumn{4}{|l|}{$\mathrm{PbtO}_{2}(\mathrm{mmHg})$} \\
\hline Baseline & $34 \pm 25$ & $31 \pm 23$ & $30 \pm 22$ \\
\hline End of injury phase $\left(\mathrm{t}_{10}\right)$ & $27 \pm 42 *$ & $26 \pm 39 *$ & $12 \pm 18^{*}, \dagger, \dagger$ \\
\hline Operative phase: pre-TVS & $57 \pm 64 *$ & $40 \pm 45^{*}$ & $21 \pm 23^{*}, \dagger, \ddagger$ \\
\hline Operative phase: post-TVS & $37 \pm 26$ & $32 \pm 23$ & $21 \pm 15 \dagger, \ddagger$ \\
\hline Resuscitation baseline $\left(\mathrm{t}_{60}\right)$ & $35 \pm 20$ & $32 \pm 18$ & $24 \pm 13 \dagger, \ddagger$ \\
\hline Resuscitation phase $\left(\mathrm{t}_{360}\right)$ & $30 \pm 10$ & $23 \pm 7$ & $25 \pm 8$ \\
\hline
\end{tabular}

$* P<.05$ vs. BL.

$\dagger P<.05$ vs. CO.

$\ddagger P<.05$ vs. BO. All others NS.

All values are mean $\pm \mathrm{SD}$.

The target hemorrhage volume was weight-based at $35 \%$ of the total blood volume to yield a shock state. A simulated prehospital bleeding time was set at 20 minutes, with half of the target hemorrhage volume removed during the first 7 minutes and the remainder removed during the next 13 minutes. ${ }^{15}$

The blood was withdrawn from the iliac artery sheath during the prehospital injury phase and stored for re-transfusion. If the mean arterial pressure decreased below $30 \mathrm{~mm} \mathrm{Hg}$, hemorrhage was stopped until the arterial pressure returned to normal and then resumed until completion of the 20-minute simulated prehospital phase. During the operative phase, $20 \%$ of the calculated blood volume was returned to the animal as whole blood. To ensure class IV shock, animals were subjected to ongoing hemorrhage $(0.15 \mathrm{~mL} / \mathrm{kg} / \mathrm{min})$ until vascular control was achieved.

Resuscitation. Groups were resuscitated and monitored for 6 hours, with measurements of central perfusion, cerebral perfusion, and endorgan function taken at standardized intervals. Initially, resuscitation included a $20 \%$ (calculated total blood volume) aliquot of whole blood. The blood pressure was titrated to a goal mean pressure of $60 \mathrm{~mm} \mathrm{Hg}$ using 1 liter intravenous fluid bolus. When animals failed a fluid challenge and required additional pharmacologic support to maintain the target blood pressure, norepinephrine (double concentrated at $8 \mathrm{mg} / 250 \mathrm{~mL}$ normal saline) was administered. Norepinephrine doses were titrated to maintain the goal central pressure.

Laboratory and histologic analysis. Laboratory collection occurred at BL and at $\mathrm{t}_{10}, \mathrm{t}_{60}, \mathrm{t}_{120}, \mathrm{t}_{180}$, $\mathrm{t}_{240}, \mathrm{t}_{300}$, and $\mathrm{t}_{360}$ minutes $\left(\mathrm{t}_{0}\right.$ starts after prehospital hemorrhage). Monitoring occurred during all phases with additional measures at $\mathrm{t}_{45}$ pre-TVS (45 minutes posthemorrhage, before TVS placement and reperfusion) and $t_{45}$ post-TVS (45 minutes posthemorrhage, after TVS reperfusion). Postmortem studies of tissue and histopathology were used to gauge end-organ damage.

Using the enzyme-linked immunosorbent assay and immunohistochemistry, cardiac ischemia was assessed postmortem by measuring nitrotyrosine content in the ischemic/reperfused cardiac tissue and myeloperoxidase activity. Neurologic injury was measured using Fluoro-Jade B staining and the TUNEL (terminal deoxyribonucleotide transferase-mediated dUTP nick end labeling) assay.

Statistical analysis. Group means of single measures were compared by analysis of variance (ANOVA). Geometric means were compared for 
measures that were more normally distributed after log-transformation. The overall test of equality of means across groups was tested and considered significant at $P<.05$ before exploring differences between group pairs. Group comparisons were conducted using a mixed model with a first-order autoregressive covariance structure for repeated measures that treated time as a categorical factor.

A sample size of 6 per group provides $80 \%$ power to detect a standardized effect size of 0.69 (or approximately 1.4 standard deviation [SD] difference) among means for the physiologic measures, an effect size of 0.75 (1.5 SD difference) for the main effect of time, and an effect size of 1.00 (or approximately $2 \mathrm{SD}$ ) for the interaction term when testing with a repeated measures ANOVA at the alpha level of 0.05 . Differences in physiologic measures detected at this power level were considered clinically significant for this study. Commercially available software (SAS 9.2; SAS Institute, Inc., Cary, NC) was used for statistical calculations.

\section{RESULTS}

Outcomes and perfusion measurements. There was no difference in mortality among the $\mathrm{CO}, \mathrm{BO}$, or NO groups $(0 \%, 0 \%$, and $17 \%$, respectively; $P=$ not significant $[\mathrm{NS}])$. The single fatality in the NO group occurred during the resuscitation phase with no obvious cause of death at necropsy. Total shed blood volume was greatest in the NO group by protocol design, given the increased time of ongoing hemorrhage in this group (CO: 1,998 \pm 307 $\mathrm{mL}$; BO: $2,087 \pm 105$; NO: 2,353 $\pm 194 \mathrm{~mL} ; P=.03$ ).

All vascular shunts remained patent after placement and throughout the resuscitation phase. A summary of perfusion measures obtained throughout the protocol is demonstrated in Table I. Compared to baseline, central aortic pressure during the operative phase, pre-TVS demonstrated an increase in the $\mathrm{CO}$ and $\mathrm{BO}$ groups after occlusion of the aorta (CO: $57 \pm 4 \mathrm{~mm} \mathrm{Hg}$ vs $138 \pm 12 \mathrm{~mm}$ $\mathrm{Hg} ; \mathrm{P}<.05$; and BO: $59 \pm 4 \mathrm{~mm} \mathrm{Hg}$ vs $146 \pm 13$ $\mathrm{mm} \mathrm{Hg} ; P<.05$, respectively), but not in the NO group (NO: $62 \pm 4 \mathrm{~mm} \mathrm{Hg}$ vs $45 \pm 4 \mathrm{~mm} \mathrm{Hg}$; $P=$ NS) (Fig $2, A)$.

Similarly, carotid flow increased during the operative phase, pre-TVS relative to baseline in the $\mathrm{CO}$ and $\mathrm{BO}$ groups after aortic occlusion, respectively (CO: $1,085 \pm 110 \mathrm{~mL} / \mathrm{min}$ vs $320 \pm 29$ $\mathrm{mL} / \mathrm{min} ; P<.05$; and BO: $862 \pm 87 \mathrm{~mL} / \mathrm{min}$ vs $259 \pm 24 \mathrm{~mL} / \mathrm{min} ; P<.05$, respectively), while flow remained unchanged in the NO group (Fig 2, B). Comparison among groups demonstrated greater central aortic pressures and rates
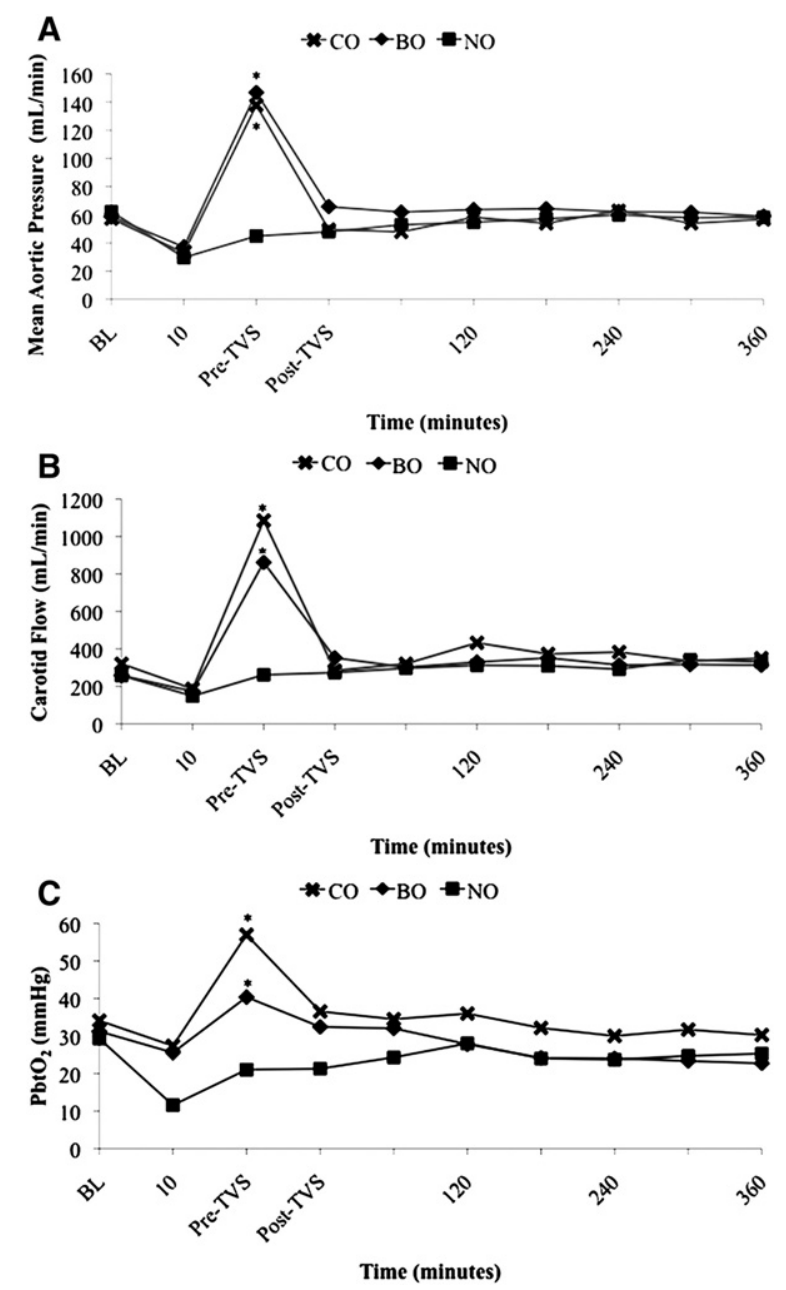

Fig 2. Measures of central aortic pressure $(A)$, carotid blood flow $(B)$, and partial pressure of brain oxygenation (PbtO2) (C) throughout the protocol phases. *Statistically significant $(P<.05)$ increases in each of these measures compared to baseline (BL) in the clamp occlusion (CO) and balloon occlusion (BO) groups during the operative phase before placement of a temporary vascular shunt (TVS). There was no increase in these measures in the no occlusion (NO) group.

of carotid flow in the $\mathrm{CO}$ and $\mathrm{BO}$ groups compared to the NO group during the operative phase pre-TVS $(P<.05)$.

All groups demonstrated a decrease in the partial pressure of brain oxygenation (PbtO2) at the end of the injury phase $\left(\mathrm{t}_{10}\right)$ compared to baseline (CO: $27 \pm 42 \mathrm{~mm} \mathrm{Hg}$ vs $34 \pm 25 \mathrm{~mm} \mathrm{Hg} ; P<.05$; BO: $26 \pm 39$ vs $\mathrm{mm} \mathrm{Hg} 31 \pm 23 \mathrm{~mm} \mathrm{Hg} ; P<.05$; and NO: $12 \pm 18 \mathrm{~mm} \mathrm{Hg}$ vs $30 \pm 22 \mathrm{~mm} \mathrm{Hg} ; P<.05)$.

$\mathrm{CO}$ and $\mathrm{BO}$ demonstrated an increase in $\mathrm{PbtO} 2$ after aortic clamping and aortic $\mathrm{BO}$ at the operative phase pre-TVS compared to baseline, respectively (CO: $57 \pm 64 \mathrm{~mm} \mathrm{Hg}$ vs $34 \pm 25 \mathrm{~mm} \mathrm{Hg}$; $P<.05$; BO: $40 \pm 45 \mathrm{~mm} \mathrm{Hg}$ vs $31 \pm 23 \mathrm{~mm} \mathrm{Hg}$; 
Table II. Laboratory assessment of global ischemia

\begin{tabular}{|c|c|c|c|}
\hline & Clamp occlusion & Balloon occlusion & No aortic occlusion \\
\hline \multicolumn{4}{|l|}{ Serum lactate $(\mathrm{mmol} / \mathrm{L})$} \\
\hline Baseline & $1.1 \pm 0.3$ & $0.9 \pm 0.2$ & $1.0 \pm 0.2$ \\
\hline End of injury phase $\left(\mathrm{t}_{10}\right)$ & $1.7 \pm 0.5$ & $1.2 \pm 0.4$ & $1.6 \pm 0.5$ \\
\hline Resuscitation baseline $\left(\mathrm{t}_{60}\right)$ & $6.6 \pm 1.1 *, \ddagger$ & $4.3 \pm 0.7^{*}, \dagger$ & $2.0 \pm 0.3 \dagger, \ddagger$ \\
\hline Resuscitation baseline $\left(\mathrm{t}_{360}\right)$ & $1.4 \pm 0.3$ & $1.4 \pm 0.3$ & $1.2 \pm 0.3$ \\
\hline \multicolumn{4}{|l|}{ Arterial pH } \\
\hline Baseline & $7.46 \pm 0.01$ & $7.49 \pm 0.01$ & $7.46 \pm 0.01$ \\
\hline End of injury phase $\left(\mathrm{t}_{10}\right)$ & $7.38 \pm 0.02$ & $7.43 \pm 0.02$ & $7.40 \pm 0.02$ \\
\hline Resuscitation baseline $\left(\mathrm{t}_{60}\right)$ & $7.24 \pm 0.03 *, \ddagger$ & $7.35 \pm 0.03^{*}, \dagger$ & $7.39 \pm 0.03 \dagger$ \\
\hline Resuscitation baseline $\left(\mathrm{t}_{360}\right)$ & $7.36 \pm 0.01 *$ & $7.45 \pm 0.01$ & $7.37 \pm 0.02 *$ \\
\hline \multicolumn{4}{|l|}{ Base excess } \\
\hline Baseline & $4.9 \pm 1.2$ & $8.0 \pm 1.2$ & $6.0 \pm 1.2$ \\
\hline End of injury phase $\left(t_{10}\right)$ & $5.5 \pm 1.0$ & $5.5 \pm 1.0$ & $4.1 \pm 1.0$ \\
\hline Resuscitation baseline $\left(\mathrm{t}_{60}\right)$ & $-3 \pm 1.1 *, \ddagger$ & $0.7 \pm 1.1^{*}, \dagger$ & $3.9 \pm 1.1^{*}, \dagger, \ddagger$ \\
\hline Resuscitation baseline $\left(\mathrm{t}_{360}\right)$ & $2.6 \pm 1.2 *, \ddagger$ & $5.5 \pm 1.2 \dagger$ & $1.5 \pm 1.3^{*}, \dagger, \ddagger$ \\
\hline
\end{tabular}

$* P<.05$ vs. BL.

$\dagger P<.05$ vs. CO.

$\ddagger P<.05$ vs. BO. All others NS.

All values are mean $\pm \mathrm{SD}$.

$P<.05$ ) (Fig 2, C). In contrast, $\mathrm{PbtO} 2$ in the NO group during the operative phase pre-TVS remained lower than baseline (NO: $21 \pm 23 \mathrm{~mm}$ $\mathrm{Hg}$ vs $30 \pm 22 \mathrm{~mm} \mathrm{Hg} ; P<.05$ ) (Fig 2, C)

Measures of physiologic derangement. Circulating measures of physiologic derangement are shown in Table II. At the beginning of the resuscitation phase $\left(\mathrm{t}_{60}\right)$, serum lactate levels were greatest in the $\mathrm{CO}$ group $(\mathrm{CO}: 6.6 \pm 1.1 \mathrm{mmol} / \mathrm{L}$ vs $\mathrm{BO}$ : $4.3 \pm 0.7 \mathrm{mmol} / \mathrm{L} ; P<.05$; and $\mathrm{NO}: 2.0 \pm 0.3$ $\mathrm{mmol} / \mathrm{L} ; P<.05$ ) (Fig $3, A)$. At this same time point, serum $\mathrm{pH}$ was lower and base deficit greater in the $\mathrm{CO}$ group compared to the $\mathrm{BO}$ and $\mathrm{NO}$ groups (serum $\mathrm{pH}=\mathrm{CO}: 7.24 \pm 0.03$ vs $\mathrm{BO}: 7.35 \pm$ $0.03 ; P<.05$; and NO: $7.39 \pm 0.03 ; P<.05$; base excess $=\mathrm{CO}:-3.0 \pm 1.1$ vs $\mathrm{BO}: 0.7 \pm 1.1 ; P<.05$; and NO: $3.9 \pm 1.1 ; P<.05)$ (Fig $3, B$ and $C$ ).

Cumulative intravenous fluid and vasopressors requirements during resuscitation are shown in Table III. Of note, there was no difference in hematocrit at the start of the resuscitation $\left(\mathrm{t}_{60}\right)$ in any of the study groups: $\mathrm{CO}(30.9 \%[+3.57 \%$ above baseline $])$; $\mathrm{BO}(35.5 \%$ [ $+3.97 \%$ above mean baseline $])$; NO (29.6\% [-0.18\% below mean baseline]). The $\mathrm{CO}$ and NO groups required greater cumulative intravenous fluids and cumulative doses of norepinephrine than the $\mathrm{BO}$ group to maintain a target central aortic pressure of $60 \mathrm{~mm} \mathrm{Hg}$ during the resuscitation phase (Fig $4, A$ and $B$ ).

During the resuscitation phase $\left(\mathrm{t}_{240}\right)$, the intravenous fluid bolus requirements were greater in the $\mathrm{CO}$ and $\mathrm{NO}$ groups than the $\mathrm{BO}$ group $(\mathrm{CO}$ : $3,833 \pm 1,835 \mathrm{~mL}$ and NO: 2,229 $\pm 1,643 \mathrm{~mL}$ vs
BO: $1,667 \pm 516 \mathrm{~mL}$, respectively; $P<.05)$. This trend continued throughout the resuscitation phase $\left(\mathrm{t}_{360}\right)(\mathrm{CO}: 4,000 \pm 1,789 \mathrm{~mL}$ and $\mathrm{NO}$ : $3,422 \pm 1,761 \mathrm{~mL}$ vs BO: $2,167 \pm 1,643 \mathrm{~mL}$, respectively; $P<.05$ ) (Fig $4, A$ ).

At the end of the resuscitation phase $\left(\mathrm{t}_{360}\right)$, the $\mathrm{CO}$ and $\mathrm{NO}$ groups required more norepinephrine than the BO group (CO: $52 \pm 28 \mathrm{mcg}$ and NO: $12 \pm$ $14 \mathrm{mcg}$ vs $\mathrm{BO} 0 \pm 0 ; P<.05)$ (Fig $4, B)$. In addition, of the 6 animals in the $\mathrm{CO}$ group, 2 required bolus doses of norepinephrine while on a continuous infusion to avoid cardiopulmonary collapse, whereas no animals in the $\mathrm{BO}$ group required vasopressor bolus.

Tissue histology. Brain and myocardial tissue stain demonstrated no differences among the groups, reflecting the limited duration of the protocol (6 hours). No difference in histologic appearance of the thoracic aorta at the occlusion sites between $\mathrm{BO}$ and $\mathrm{CO}$ groups was observed.

\section{DISGUSSION}

This study demonstrates the feasibility of resuscitative aortic $\mathrm{BO}$ in a large animal model of end-stage hemorrhagic shock. Endovascular BO resulted in increases in central aortic pressure, carotid flow, and partial oxygenation pressure of the brain that were equal to those increases associated with open clamping of the aorta. In contrast to resuscitative thoracotomy with aortic clamping, findings from this study demonstrate that endovascular BO results in less acidosis and lower resuscitative fluid and pressor requirements. 

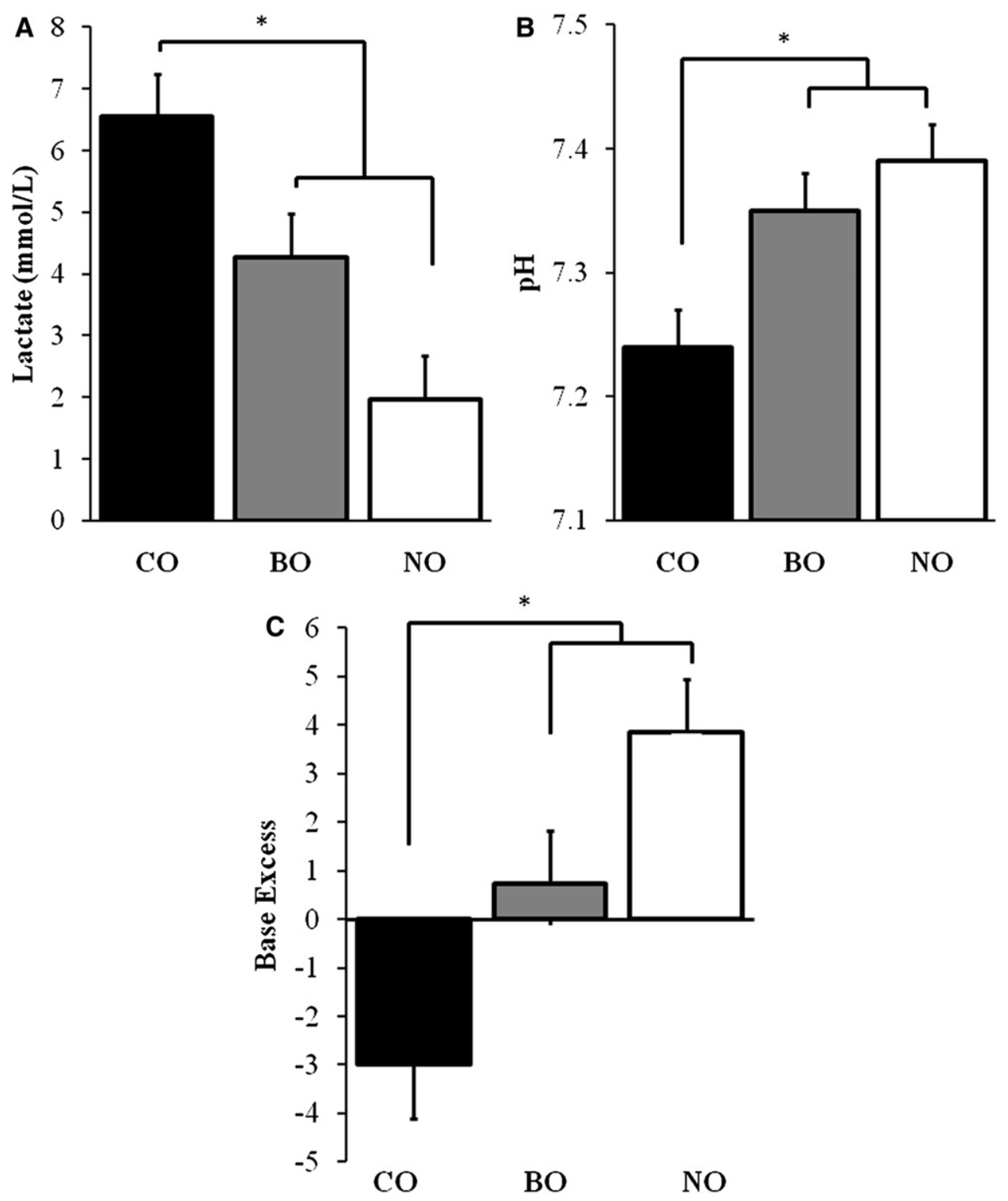

Fig 3. Measures of serum lactate $(A), \mathrm{pH}(B)$, and base excess $(C)$ at the beginning of the resuscitation phase $\left(\mathrm{t}_{60}\right)$ in the clamp occlusion $(\mathrm{CO})$, balloon occlusion $(\mathrm{BO})$, and no occlusion $(\mathrm{NO})$ groups. $(A) *$ Lactate in the CO group was significantly greater than both $\mathrm{BO}$ and NO groups $(P<.05)$, and lactate in the $\mathrm{BO}$ group was statistically greater than the NO group with no aortic occlusion $(P<.05) .(B) *$ The $\mathrm{pH}$ was significantly less in the $\mathrm{CO}$ group than the $\mathrm{BO}$ and NO groups $(P<.05)$, and the $\mathrm{pH}$ in the $\mathrm{BO}$ group was significantly less than the NO group $(P<.05)$. $(C) *$ The base excess was significantly less in the $\mathrm{CO}$ compared to the $\mathrm{BO}$ and $\mathrm{NO}$ groups $(P<.05)$, and the base excess level in the $\mathrm{BO}$ group was significantly less than the NO group $(P<.05)$.

Histologic examination of the aorta revealed no adverse effects associated with BO.

Control of bleeding and preservation of central perfusion in the setting of noncompressible hemorrhage remains a dilemma in civilian and military settings. Holcomb et $\mathrm{al}^{1}$ reviewed information on U.S. Special Operations Forces killed in action during the wars in Iraq and Afghanistan and determined that $50 \%$ of potentially survivable deaths were related to uncontrolled hemorrhage. In their conclusion, the authors called for improved methods of intravascular or intracavitary hemostasis that could be rapidly deployed as a resuscitative maneuver.

In a separate study by Kelly et al, ${ }^{2}$ uncontrolled hemorrhage again was found to be the leading cause of potentially preventable deaths of U.S. troops killed on the battlefield. Civilian experience with this injury pattern also has been reported in series focused on resuscitative thoracotomy, 
Table III. Comparison of cumulative resuscitation requirements

\begin{tabular}{|c|c|c|c|}
\hline & Clamp occlusion & Balloon occlusion & No aortic occlusion \\
\hline \multicolumn{4}{|c|}{ Cumulative IV fluid volume (mL) } \\
\hline Resuscitation phase $\left(\mathrm{t}_{60}\right)$ & 0 & 0 & $167 \pm 408$ \\
\hline Resuscitation phase $\left(\mathrm{t}_{120}\right)$ & $2,167 \pm 1,329$ & $667 \pm 816$ & $667 \pm 516$ \\
\hline Resuscitation phase $\left(t_{240}\right)$ & $3,833 \pm 1,835^{*}$ & $1,667 \pm 1,870$ & $2,229 \pm 1,643^{*}$ \\
\hline Resuscitation phase $\left(\mathrm{t}_{360}\right)$ & $4,000 \pm 1,789 *, \ddagger$ & $2,167 \pm 1,643^{*}$ & $3,422 \pm 1,761 *, \ddagger$ \\
\hline \multicolumn{4}{|c|}{ Cumulative norepinephrine (mcg) } \\
\hline Resuscitation phase $\left(\mathrm{t}_{60}\right)$ & 0 & 0 & 0 \\
\hline Resuscitation phase $\left(t_{120}\right)$ & $5 \pm 7$ & 0 & $0 \pm 1$ \\
\hline Resuscitation phase $\left(t_{240}\right)$ & $27 \pm 20 *, \ddagger$ & 0 & $4 \pm 7 \ddagger$ \\
\hline Resuscitation phase $\left(\mathrm{t}_{360}\right)$ & $52 \pm 28^{*}, \ddagger$ & 0 & $12 \pm 14^{*}, \dagger, \dagger$ \\
\hline
\end{tabular}

including a recent study by Seamon et al. ${ }^{16}$ Of 50 patients in this study, 8 survived resuscitative thoracotomy. $^{16}$

Findings in the model used in this study corroborate other researchers' experiences in the management of ruptured aortic aneurysms. In studies by Mehta et al, ${ }^{12}$ Krokos et al, ${ }^{13}$ and Mayer et $\mathrm{al}^{14}$ reporting the use of endovascular techniques to manage ruptured aneurysms, an aortic occlusion balloon is described as an initial, stabilizing maneuver. Notably, BO has been shown as a stabilizing tactic in cases when open endoaneurysmorrhaphy is used as the method of repair. ${ }^{17,18}$ In these instances we advocate hemostatic resuscitation, including permissive hypotension in combination with initiation of central venous access and balanced blood product transfusion.

In most cases, ultrasonographic guidance is used to identify the femoral artery, which is accessed using a modified Seldinger technique with placement of a 5-Fr sheath into the femoral and external iliac artery. Under fluoroscopic guidance, a 0.035-inch guidewire is advanced into the descending thoracic aorta. A larger sheath is then exchanged over this wire after an incision at the skin insertion site. It is through this larger sheath that the compliant aortic occlusion balloon is inserted over the wire to its position in the descending thoracic aorta. After positioning, the balloon is inflated using a mix of saline and contrast to allow visualization of the balloon as the maneuver is accomplished.

Alternatively, a similar sequence of steps can be used to insert the wire and balloon through the brachial artery into the thoracic aorta. Balloon inflation decreases blood loss and supports perfusion while resuscitation is initiated, anesthesia induced, and surgical hemostasis is established. ${ }^{17,18}$
Use of this adjunct in the setting of ruptured aneurysms has contributed to the first decrease in mortality after this lethal disease in approximately 4 decades. In that ruptured aneurysms represent a model of noncompressible torso hemorrhage, it is plausible that this benefit may translate to traumatic forms of hemorrhagic shock as well. ${ }^{12-14}$

Current findings support the results from previous studies performed in models of cardiac arrest and cardiopulmonary resuscitation. Spence et $\mathrm{al}^{19}$ showed in a canine model that aortic BO during open cardiac massage resulted in a $130 \%$ increase in central aortic pressure and $100 \%$ improvement in cerebral flow. Sesma and colleagues ${ }^{20}$ performed a similar study examining BO during external chest compressions in a porcine model of cardiac arrest. In this latter study, the authors demonstrated increases in coronary $(150 \%)$ and cerebral $(200 \%)$ perfusion after inflation of the aortic balloon. Finally, Gedeborg et $\mathrm{al}^{21}$ reported similar effectiveness of $\mathrm{BO}$ in a porcine model of ventricular fibrillation.

In one of the few studies examining aortic BO in the setting of hemorrhagic shock, Poli de Figueiredo et $\mathrm{al}^{22}$ showed its effectiveness with concomitant administration of hypertonic saline in a canine model. This group concluded that the 2 therapies should be considered as complementary measures for the management of end-stage hemorrhagic shock.

Kralovich et $\mathrm{al}^{23}$ reported a potentially negative impact of aortic occlusion in a porcine model as central hypertension with ventricular strain and impaired function. The conclusions from that publication are relevant to the current study in which central aortic pressures increased to levels well above baseline after inflation of the aortic balloon (Fig 2). Although this study does not demonstrate any 

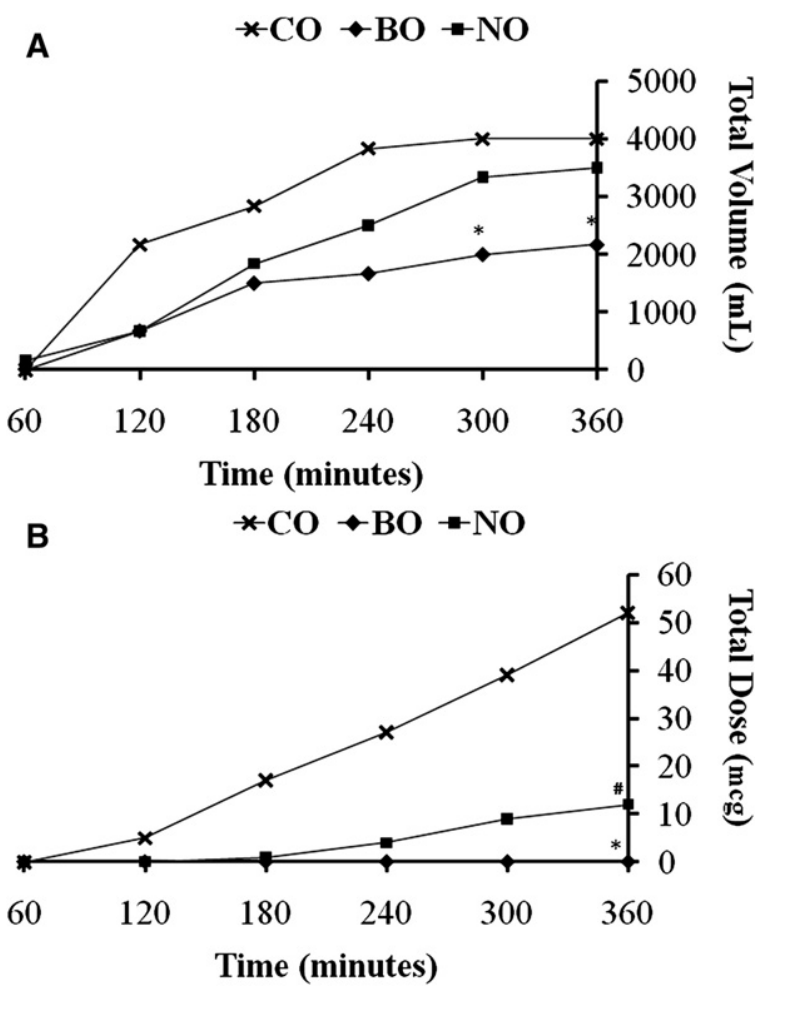

Fig 4. Cumulative fluid $(A)$ and norepinephrine $(B)$ requirements throughout the resuscitative phase of the protocol in the clamp occlusion $(\mathrm{CO})$, balloon occlusion (BO), and no occlusion (NO) groups. $(A) *$ Denotes significantly less cumulative fluid requirements in the $\mathrm{BO}$ group compared to the $\mathrm{CO}$ and NO groups $(P<.05)$. There was no difference in the cumulative fluid requirements between the $\mathrm{CO}$ and NO groups. $(B) *$ Denotes the $\mathrm{BO}$ group required significantly less total doses of norepinephrine compared to the $\mathrm{CO}$ and $\mathrm{NO}$ groups $(P<.05)$. \#Denotes the NO group required significantly less total doses of norepinephrine than the CO group $(P<.05)$.

apparent adverse effects on the left ventricles from the clamp or the BO, the potential for negative effects of severe transient central hypertension would be better assessed in a survival model.

In that regard, we recently demonstrated in a model of abdominal hemorrhage that direct transabdominal control of bleeding results in less physiologic derangement than hemorrhage control following transthoracic or transabdominal aortic clamping. ${ }^{24}$ In contrast to open aortic clamping, one advantage of resuscitative aortic balloon occlusion is that it can be applied incrementally while ongoing hemostatic resuscitation restores the patient's blood volume. Based on the findings of these two studies, we surmise that, to a point, the body's autoregulatory mechanisms are superior to a mechanical clamp at appropriately distributing the remaining blood volume to vital tissue beds without inducing hemicorporal ischemia. However after some threshold, if central perfusion pressure to the heart and brain are not supported cardiovascular collapse and death will occur.

Despite evidence supporting the use of aortic $\mathrm{BO}$, the technique has not been implemented widely in clinical practice. This lack of use may be related to limitations in current technology, which is designed primarily for the management of aneurysm disease. Most compliant aortic occlusion balloons today expand to a diameter of $42 \mathrm{~mm}$ and require sheaths ranging from 12 to $14 \mathrm{Fr}$. Such dimensions are necessary for treating dilated aortas and the large sheaths necessary for today's devices are easily placed by surgeons with the aid of fluoroscopy in the operating room. Current technology however is not amenable to trauma scenarios which would require rapid, lower profile arterial access in a younger patient population with normal caliber aortas.

Once technology is improved and further experience with this approach is gained, simulation and laboratory training in endovascular balloon aortic occlusion for resuscitation in shock should be incorporated into hands-on courses such as the Advanced Trauma Operative Management (ATOM; http://atomcourse.com/) and the Advanced Surgical Skills for Exposure in Trauma (ASSET; http:// www.facs.org/xtrauma/education/asset.html), which are offered by the American College of Surgeons (Chicago, IL).

Limitations of this technology and approach notwithstanding, the burden of injury from the wars in Iraq and Afghanistan has necessitated a reappraisal of management techniques for hemorrhagic shock. And, like other operative methods that have been transformed as a result of battlefield requirements (eg, tourniquets, topical hemostatic agents, and resuscitation strategies), the technique of resuscitative aortic occlusion also stands to be advanced as a result of recent wartime experience.

The model used in this study has limitations. Foremost, it provides a short reperfusion period without survival that may have shown resolution of the adverse physiologic profile in the $\mathrm{CO}$ group and no benefit from BO. The small sample size used in this study also precluded detection of any mortality difference between groups, whereas the survival rates that were greater than expected raises the possibility that the degree of hemorrhage was insufficient. This factor is relevant because resuscitative aortic occlusion is used as a final measure just before or after cardiovascular collapse. Use of a model that has too little hemorrhage and an artificial vascular injury site may not 
accurately quantify the effect of these maneuvers in an actual clinical scenario.

The artificial injury site (ie, large-caliber sheath) was chosen to control the variable of hemorrhage and allow the study's focus to be on the method of aortic occlusion. Less controlled methods of intraabdominal hemorrhage might have been more realistic but would also be prone to variability, thus limiting the model's ability to describe aortic occlusion methods. Despite limitations this model provides a basis from which to refine the technique of resuscitative aortic $\mathrm{BO}$, including characterization of varied occlusion times and the development of smaller profile, trauma-specific devices.

In conclusion, this study reports results from a novel model of resuscitative $\mathrm{BO}$ of the aorta in end-stage hemorrhagic shock. Endovascular BO is feasible and increases central aortic pressure and perfusion to the brain with less physiologic disturbance than resuscitative thoracotomy with aortic clamping. Improvements in technology including development of lower profile, trauma-specific aortic occlusion systems may allow wider application of this adjunct in cases of noncompressible hemorrhage and even cardiac arrest.

\section{REFERENCES}

1. Holcomb JB, McMullin NR, Pearse L, Caruso J, Wade CE, Oetjen-Gerdes L, et al. Causes of death in U.S. Special Operations Forces in the global war on terrorism: 2001-2004. Ann Surg 2007;245:986-91.

2. KelllyJF, Ritenour AE, McLaughlin DF, Bagg KA, Apodaca AN, Mallak CT, et al.J Injury severity and causes of death from Operation Iraqi Freedom and Operation Enduring Freedom: 2003-2004 versus 2006. Trauma 2008;64(2 Suppl):21-6; discussion 26-7.

3. White JM, Stannard A, Burkhardt GE, Eastridge BJ, Blackbourne LH, Rasmussen TE. The epidemiology of vascular injury in the wars in Iraq and Afghanistan. Ann Surg 2011;253:1187-9.

4. Beekley AC, Sebesta JA, Blackbourne LH, Herbert GS, Kauvar DS, Baer DG, et al. Prehospital tourniquet use in operation Iraqi Freedom: effect on hemorrhage control and outcomes. J Trauma 2008;64(2 Suppl):28-37; discussion 37.

5. Kragh JF, Walters TJ, Baer DG, Fox CJ, Wade CE, Salinas J, et al. Survival with emergency tourniquet use to stop bleeding in major limb trauma. Ann Surg 2009;249:1-7.

6. Ledgerwood AM, Kazmers M, Lucas CE. The role of thoracic aortic occlusion for massive hemoperitoneum. J Trauma 1976;16:610-5.

7. Edens JW, Beekley AC, Chung KK, Cox ED, Eastridge BJ, Holcomb JB, et al. Longterm outcomes after combat casualty emergency department thoracotomy. J Am Coll Surg 2009;209:188-97.

8. Rhee PM, Acosta J, Bridgeman A, Wang D, Jordan M, Rich N. Survival after emergency department thoracotomy: review of published data from the past 25 years. J Am Coll Surg 2000;190:288-98.
9. Working Group, Ad Hoc Subcommittee on Outcomes, American College of Surgeons, Committee on Trauma. Practice management guidelines for emergency department thoracotomy. Working Group, Ad Hoc Subcommittee on Outcomes, American College of Surgeons-Committee on Trauma. J Am Coll Surg 2001;193:303-9.

10. Emergency war surgery. 3rd revision. Washington (DC): Borden Institute; 2004

11. Chaikof EL, Brewster DC, Dalman RL, Makaroun MS, Illig KA, Sicard GA, et al. The care of patients with an abdominal aortic aneurysm: the Society for Vascular Surgery practice guidelines. J Vasc Surg 2009;50(4 Suppl):2-49.

12. Mehta M, Taggert J, Darling RC 3rd, Chang BB, Kreienberg PB, Paty PS, et al. Establishing a protocol for endovascular treatment of ruptured abdominal aortic aneurysms: outcomes of a prospective analysis. J Vasc Surg 2006;44:1-8.

13. Krokos CD, Harkin DW, Giannakou A, Gerassimidis TS Mortality after endovascular repair of ruptured abdominal aortic aneurysms: a systemic review and meta-analysis. Arch Surg 2009;144:770-8.

14. Mayer D, Pfammatter T, Rancic Z, Hechelhammer L, Wilhelm M, Veith FJ, et al. 10 years of emergency endovascular aneurysm repair for ruptured abdominal aortoiliac aneurysms: lessons learned. Ann Surg 2009;249:510-5.

15. Frankel DA, Acosta JA, Anjaria AJ, Porcides RD, Wolf PL, Coimbra R, Hoyt DB. Physiologic response to hemorrhagic shock depends on rate and means of hemorrhage. J Surg Res 2007;143:276-80

16. Seamon MJ, Pathak AS, Bradley KM, Fisher CA, Gaughan JA, Kulp H, et al. Emergency department thoracotomy: still useful after abdominal exsanguination? J Trauma 2008;64:1-7.

17. Arthurs ZM, Starnes BW, See C, Andersen C. Clamp before you cut: proximal control of ruptured abdominal aortic aneurysms using endovascular balloon occlusion-case reports. Vasc Endovascular Surg 2006;40:149-55.

18. Arthurs ZM, Sohn VY, Starnes BW. Ruptured abdominal aortic aneurysms: remote aortic occlusion for the general surgeon. Surg Clin North Am 2007;87:1035-45.

19. Spence PA, Lust RM, Chitwood WR Jr, Iida H, Sun YS, Austin EH 3rd. Transfemoral balloon aortic occlusion during open cardiopulmonary resuscitation improves myocardial and cerebral blood flow. J Surg Res 1990;49: $217-21$.

20. Sesma J, Labandeira J, Sara MJ, Espila JL, Arteche A, Saez MJ. Effect of intra-aortic occlusion balloon in external thoracic compressions during CPR in pigs. Am J Emerg Med 2002;20:453-62.

21. Gedeborg R, Rubertsson S, Wiklund L. Improved haemodynamics and restoration of spontaneous circulation with constant aortic occlusion during experimental cardiopulmonary resuscitation. Resuscitation 1999;40:171-80.

22. Poli de Figueiredo LF, Peres CA, Attalah AN, Romaldini H, Miranda F Jr, Francisco J Jr, Burihan E. Hemodynamic improvement in hemorrhagic shock by aortic balloon occlusion and hypertonic saline solutions. Cardiovasc Surg 1995;3:679-86.

23. Kralovich KA, Morris DC, Dereczyk BE, Simonetti V, Williams M, Rivers EP, Karmy-Jones R. Hemodynamic effects of aortic occlusion during hemorrhagic shock and cardiac arrest. J Trauma 1997;42:1023-8.

24. White JM, Cannon JW, Stannard A, Burkhardt GE, Spencer JR, Williams KL, et al. Direct vascular control results in less physiologic derangement than proximal aortic clamping in a porcine model of non-compressible extra-thoracic torso hemorrhage. J Trauma. In press. 